${ }^{* * *}$ please note that this is a non-peer reviewed EarthArXiv preprint ${ }^{* * *}$

\title{
Prototyping a collaborative data curation service for coastal science
}

Evan B. Goldstein 1*, Anna E. Braswell 2, Caitlin M. Mc Shane 3

1 Department of Geography, Environment, and Sustainability, University of North Carolina at Greensboro, Greensboro, NC, USA

2 Fisheries and Aquatic Sciences Program, School of Forest Resources and Conservation, University of Florida/IFAS, Gainesville FL, 32603, USA

3 Department of Geography, University of Colorado Boulder, Boulder CO, 80301, USA

*Corresponding author:

Email: ebgoldst@uncg.edu

Twitter: @ebgoldstein

ORCiD:

EBG: 0000-0001-9358-1016

AEB: 0000-0002-3677-0635

CMM: 0000-0001-7194-0575

\begin{abstract}
The growing push for open data has resulted in an abundance of data for coastal researchers, which can lead to problems for individual researchers related to discoverability of relevant data. One solution is to explicitly develop services for coastal researchers to help curate data for discovery, hosting discussions around reuse, community building, and finding collaborators. To develop the idea of a coastal data curation service, we investigate aspects of the UNESCO International Coastal Atlas Network member sites that could be used to build a curation service. We develop a minimal example of a coastal data curation service, deploy this as a website, and describe the next steps to move beyond the prototype phase. We envision a coastal data curation service as a way cultivate a community focused on coastal data discovery and reuse.
\end{abstract}

\section{Motivation}

There is a broad push in the earth and environmental science for Findable, Accessible, Interoperable and Reusable data (FAIR data; Wilkinson et al., 2016) from scientists, scientific societies, publishers, and funders (e.g., Stall et al., 2018; 2019). This growing volume of open data available for coastal researchers enables data-driven investigations and large-scale data analysis to develop insight into complex coastal issues, which often lie at the intersection of 
physical, social, and biological processes. A growing compendium of data presents new challenges, one example being discovery - how does a researcher discover if new or useful data already exists? Just as it is challenging to keep up with published literature, it is a challenge to keep up with available and published data.

Relevant data is stored in a variety of places: disciplinary-specific repositories, location-specific repositories, institutional repositories, funder repositories, on personal/project websites, or in non-public facing places (i.e., lab/office hard drives as dark data; Heidorn 2008). The existence of a specific data repository may also not be known to a researcher who could benefit from data contained within it - i.e., individual researchers must discover a repository in order to use open data. The large number of repositories listed by the re3data.org project (Pampel et al., 2013) is a testament the accelerated growth in number of repositories. Stand-alone data descriptor articles aid in dataset discovery, published in venues such as Earth System Science Data (Pfeiffenberger and Carlson, 2011), Earth and Space Science (Hanson, 2014), Geoscience Data (Allan, 2014), and Scientific Data (Scientific Data, 2014). Frequently data arrives without its own descriptor article, is discussed and reported in individual manuscripts, and may even be present solely in the manuscript or in supplementary material.

The growing library of published data, in a variety of repositories, is analogous to the rapid growth in the number of scholarly manuscripts (e.g., Bornmann and Mutz 2015) in a growing number of journals (e.g., Tenopir and King 2014). This issue is well known in coastal research, where relevant literature spans disciplinary boundaries and is published in an almost dizzying array of venues split by discipline, prestige, geographic location, language, and intended audience. Researchers must keep track of an expanding number of relevant publications per unit time, as well as a growing list of journals, echoing the age-old problem of working to understand the flood of scholarly works (e.g., Blair, 2010). Discovery of new research has become a significant time commitment for scholars (e.g., Priem, 2013). The challenge of discovery has motivated the development of new services and platforms - new search engines (e.g., Google Scholar), social networks (e.g., ResearchGate), recommendation services (e.g., Shetty et al., 2021), and curation services (e.g., preLights, Peeriodicals, Peer Community In, Papers with Code). These services are geared mostly toward manuscripts, though some analogous services exist for data alone (e.g., DataCite Search, Google Dataset Search, Data is Plural; Singer-Vine, 2021).

We focus here on envisioning a new data curation service to aggregate relevant published data for specific end-users (in this case, coastal researchers) and act as a communal, interdisciplinary space that intentionally generates discussion on various aspects of data products (Figure 1). This space is different than a data portal, whose role is focused on harmonizing and presenting data relevant for a given geographic region or topic (e.g., Lazarus et al. 2020). Instead, we imagine a curation service would not host or harmonize data, instead it would allow community members to contribute and highlight coastal datasets that could be of interest to others. A curation service 
works to point coastal scientists toward relevant datasets archived in various repositories. Data authors can then still deposit data in any repository, which might be subject to funder mandates, institutional mandates, or preferences based on discoverability, submission ease, cost, discipline, or other factors.

The biggest benefit of a curation service would be to permit interactions around relevant data, such as fostering community discussion around particular datasets and allowing community members to aid in the curation process. We believe hosting discourse around a data set could encourage critical reflection, interaction, and collaboration. Each dataset could also have its own dialogue or forum where people can ask or answer questions pertaining to the data, point out previous uses of the data (e.g., manuscripts, preprints, posters, talks, blogs), link to open source code for working with specific datasets, and discuss ways that a highlighted dataset can be used in interdisciplinary research. Users could discuss potential uses of data as well as problems encountered while using data. This type of discussion is usually restricted to physical conversations and emails. By developing an open forum for discourse surrounding data usage, specifically tied to the dataset, this approach will further develop a community around coastal data science. An online discussion platform could be used by researchers to actively develop ideas to apply data across multiple subject areas and also promote individual datasets to the coastal community - not just to academic coastal researchers, but to practitioners, managers, consultants, and others working in the coastal realm. In the following sections we investigate online networks that have attempted to coalesce data for the coastal science community. Through this investigation we highlight the pitfalls and successes of prominent data service providers in the coastal domain - Coastal Atlases . We use our findings to propose a flexible lightweight data curation service that addresses these issues and offers a platform to enhance data visibility and foster community discussion.

\section{UNESCO International Coastal Atlas Network (ICAN)}

To understand the features and functions of a new coastal data curation service, we examine an existing network of coastal data providers. Our goal is to understand what data curation services already exist, how it is operationalized, how it differs from a traditional data portal, and any potential problems to be avoided. We examine the UNESCO International Coastal Atlas Network (ICAN), a group of organizations that aims to increase sharing of data relevant to coastal or marine processes and to establish global-level data interoperability (Wright et al. 2011). Member sites serve as both a curation service - presenting a selection of data specific to a location or geography - and a data portal, hosting and potentially harmonizing data. Through their members' locational data curation, ICAN works to expand data interoperability and data sharing by creating a set of best practices for atlas establishment, such as utilizing a single, unified (but proprietary) mapping software. We investigate 31 ICAN member sites and 11 nonmember atlas sites to examine features and functions that are relevant for curation services (Figure 2; Supplemental Table 1). ICAN members seem to individually collect and curate coastal 
data that are then typically stored in their own large online repositories or as a series of external links designed to take you to the homepage of the institution housing the data product. Many of the individual ICAN members host some of the same datasets, particular NOAA or USGS created datasets.

We specifically focus on the role of ICAN members as data curators - their function as pointers to datasets that they do not host. With this function come problems that affect the functionality of the atlas. Many datasets on the ICAN member sites do not use persistent identifiers (e.g., Digital Object Identifiers; DOIs) to link to curated, non-hosted data. This problem is not surprising, as many datasets do not have DOIs or any other type of persistent identifier (Goldstein et al. 2017). The lack of any persistent identifier results in datasets across numerous atlases suffering from link rot issues - the web addresses no longer resolve, or no longer link to the original dataset. A key aspect for data curation services, since they are not hosts, is to make sure that datasets discussed are always available via a persistent identifier. Researchers can then programmatically access data using the DOI or identifier (and appropriate retrieval techniques for individual repositories).

Some coastal atlases do perform a few of the functions of a data curation service. Well-designed atlases (i.e., the Maryland Coastal Atlas:

https://dnr.maryland.gov/ccs/coastalatlas/Pages/default.aspx ) highlight data through applications such as ESRI ArcGIS Story Maps or blog posts. These added pieces help users to understand the development and possible uses of open coastal data. Although coastal atlases are typically based around geography, they tend to bring data from multiple sources and portals together in one place. This service can help coastal atlas users discover and connect to other coastal data resources. Finally, coastal atlases often to cater to many different user groups, including audiences with varying data literacy. For example, for less experienced users, coastal atlases let you view data of interest on a map through an easy-to-use interface. Often this data is available for download and analysis for the more experienced data user. These three qualities of coastal atlases make data more available and discoverable to broad audiences across the designated geography of the atlas.

\section{A new prototype curation service for coastal data}

We use the UNESCO coastal atlases as a reference point for developing a service that functions less like a portal and more like a curation service. We envision a new curation service that points researchers toward relevant data but also intentionally fosters community collaboration and data discovery. A service need to be designed for researchers and end users to easily discover, access, and discuss data products. A minimal example is shown in Figure 3 and is currently deployed (https://copecomet.github.io/Coastal-Data/). There are three core components. First is an introduction page that describes the goals of the project and how to contribute. Second, individual dataset entries, each with a predefined format. Any user can contribute an entry via 


\section{${ }^{* * *}$ please note that this is a non-peer reviewed EarthArXiv preprint ${ }^{* * *}$}

adding a markdown document to the public GitHub repository. A template for dataset entries are provided in the repository. Third, a discussions/commenting section that is attached to each post, where anyone can type comments, discussion points, links to code and other relevant info, and flag other users via their GitHub usernames. This system is built on top of GitHub, similar to other new scholarly communication tools (e.g., JOSS; Smith et al., 2018).

Aspects of this curation service model informed by the Coastal atlases, such as introductory pages that describe the scope of the data within, and datasets each with entries based on metadata. Atlases help to potentially combat the overload of datasets being published in different repositories and venues by creating a single source for data information. The difference in our design is that a curation service would explicitly point towards multiple data hosts and is not solely focused around a location or region. As data are not directly stored by the curation service, searching, accessing, and discussing data is a relatively lightweight service that overlays the multitude of repositories currently housing data products. Each entry will have a link to the data download page and/or a DOI that the user can utilize if they wish to access data. An automated link checking algorithm circumvents issues such as link rot thereby providing a consistent and reliable data source for scientists and managers.

This curation service will act as a registry of entries on coastal data products. Each entry will contain general information about a dataset and will also include comment sections for caveats, potential data linkages, uncertainty, and help wanted. In addition to general information, data entries will include links to publications that have used the data, blog posts, and/or tutorial pages. To attempt to include researchers with less programmatic ability, links to code snippets that can download, transform, or manipulate data will also be provided on the page.

Discussions threads attached to each data entry can focus on recommendations for other relevant datasets and interdisciplinary discussions about data use. We envision that potential collaborations could establish in these discussion threads to connect scientists to data and other researchers while generating constructive dialogue about data products. As the service builds outward, a service could periodically host guest articles about data trends and novel data products where community members can respond and engage with data scientists from various backgrounds.

Publicizing individual data products will enhance exposure for both the dataset and for potential users and will generate more robust conversation about specific products. Using available data descriptors and published studies, a brief summary of the methodology, validation, uncertainty, and usage will be provided to a discussion forum where community members can ask questions or submit their own anecdotal experience of using that dataset. Community members can rate the data across a number of categories including ease of use, accuracy, and general applicability.

\section{Future Directions}


We have presented and described a minimal example of a coastal data curation service, which is based on our investigation of UNESCO coastal atlases. A full featured coastal data curation service could be further developed prototype work, but a key to developing a rich experience for users is actively growing a community of researchers who read and contribute to the effort. We believe that hosting highlighting coastal datasets and hosting discussion surrounding the use of specific datasets could incentivize users to read and then potentially contribute to the effort i.e., the service should offer some value to users, and hope that those users then contribute new datasets or pointing new people to the service.

\section{Code availability:}

Our minimal example of our curation service is currently deployed here: https://copecomet.github.io/Coastal-Data/

The source code for the site is available here: https://github.com/CoPeCOMET/Coastal-Data

\section{Acknowledgement:}

The authors gratefully acknowledge support from US National Science Foundation (1939954, 1953412 to EBG; 1940006, 1924670 to Braswell), a US National Science Foundation Graduate Research Fellowship under Grant No. (DGE 1650115) to Mc Shane, and an Early-Career Research Fellowship from the Gulf Research Program of the National Academies of Sciences, Engineering, and Medicine (to EBG). The content is solely the responsibility of the authors and does not necessarily represent the official views of the Gulf Research Program of the National Academies of Sciences, Engineering, and Medicine.

\section{References:}

Allan, R., 2014. Geoscience data. Geosci. Data J., 1: 1. doi:10.1002/gdj3.3 Bornmann, L. and Mutz, R., 2015. Growth rates of modern science: A bibliometric analysis based on the number of publications and cited references. Journal of the Association for Information Science and Technology, 66(11), pp.2215-2222.

Blair, A. M. (2010). Too much to know: Managing scholarly information before the modern age. Yale University Press.

Goldstein, J.C., Mayernik, M.S. and Ramapriyan, H.K., 2017. Identifiers for earth science data sets: Where we have been and where we need to go. Data Science Journal, 16.

Hanson, B., 2014. AGU to Launch a New Open-Access Journal Spanning the Earth and Space Sciences. Eos, Transactions American Geophysical Union, 95(6), 56-56.

Heidorn, P.B., 2008. Shedding light on the dark data in the long tail of science. Library trends, 57(2), pp.280-299. 


\section{${ }^{* * *}$ please note that this is a non-peer reviewed EarthArXiv preprint ${ }^{* * *}$}

Lazarus ED, S Aldabet, CEL Thompson, CT Hill, RJ Nicholls, JR French, S Brown, EL Tompkins, ID Haigh, IH Townend, EC Penning-Rowsell, (2020), The UK needs an open data portal dedicated to coastal flood and erosion hazard risk and resilience, EarthArXiv https://doi.org/10.31223/X5989C

O’Dea, L., Cummins, V., Wright, D., Dwyer, N. and Ameztoy, I., 2007. Report on Coastal Mapping and Informatics Trans-Atlantic Workshop 1: Potentials and Limitations of Coastal Web Atlases. University College Cork, Ireland, Coastal \& Marine Resources Centre.

$<$ http://workshop1.science.oregonstate.edu/final_rpt $>$

Pampel, H., Vierkant, P., Scholze, F., Bertelmann, R., Kindling, M., Klump, J., Dierolf, U., 2013. Making research data repositories visible: The re3data. org registry. PloS one, $8(11)$, e78080.

Pfeiffenberger, H., Carlson, D., 2011. "Earth System Science Data" (ESSD)-A Peer Reviewed Journal for Publication of Data. D-Lib Magazine, 17(1/2).

Priem, J. Beyond the paper. Nature 495, 437-440 (2013). https://doi.org/10.1038/495437a

Scientific Data, 2014. More bang for your byte. Sci. Data, 1, 140010.

Shetty, Namit, A Verstak, K J Hwang, L Jin, P David, A. Acharya (2021) Scholar

Recommendations Reloaded! Fresher, More Relevant, Easier

https://scholar.googleblog.com/2021/02/scholar-recommendations-reloaded.html

Smith AM, Niemeyer KE, Katz DS, Barba LA, Githinji G, Gymrek M, et al. Journal of Open Source Software (JOSS): design and first-year review. PeerJ Computer Science. PeerJ; 2018;4: e147. https://doi.org/10.7717/peerj-cs.147

Stall, S. Yarmey, L.; Cutcher-Gershenfeld, J.; Hanson, B.; Lehnert, K.; Nosek, B.; Parsons, M.; Robinson, E.; Wyborn, L. Make scientific data FAIR. Nature 2019, 570, 27-29. https://doi.org/10.1038/d41586-019-01720-7

Stall, S., et al. (2018). Advancing FAIR data in Earth, space, and environmental science. Eos, 99. DOI: https://doi.org/10.1029/2018EO109301

Singer-Vine, J. (n.d.). Data is plural. Retrieved March 09, 2021, from https://tinyletter.com/datais-plural

Tenopir, C. and King, D.W., 2014. The growth of journals publishing. In The future of the academic journal (pp. 159-178). Chandos Publishing.

Wright, D.J.1, Watson, S.2, Bermudez, L.2, Cummins, V.3, Dwyer, N.3, O’Dea, L.3, Nyerges, T., Benoit, G., Berman, M., Helly J., and Uhel, R., 2007. Report on Coastal Mapping and Informatics Trans-Atlantic Workshop 2: Coastal Atlas Interoperability. Oregon State University, Corvallis, Oregon, USA $<$ http://workshop1.science.oregonstate. edu/final_rpt2/>. 
Wright, D.J., Cummins, V. and Dwyer, E., 2011. The international coastal atlas network. In Coastal Informatics: Web Atlas Design and Implementation (pp. 229-238). IGI Global.

Wilkinson, M., Dumontier, M., Aalbersberg, I. et al. The FAIR Guiding Principles for scientific data management and stewardship. Sci Data 3, 160018 (2016).

https://doi.org/10.1038/sdata.2016.18

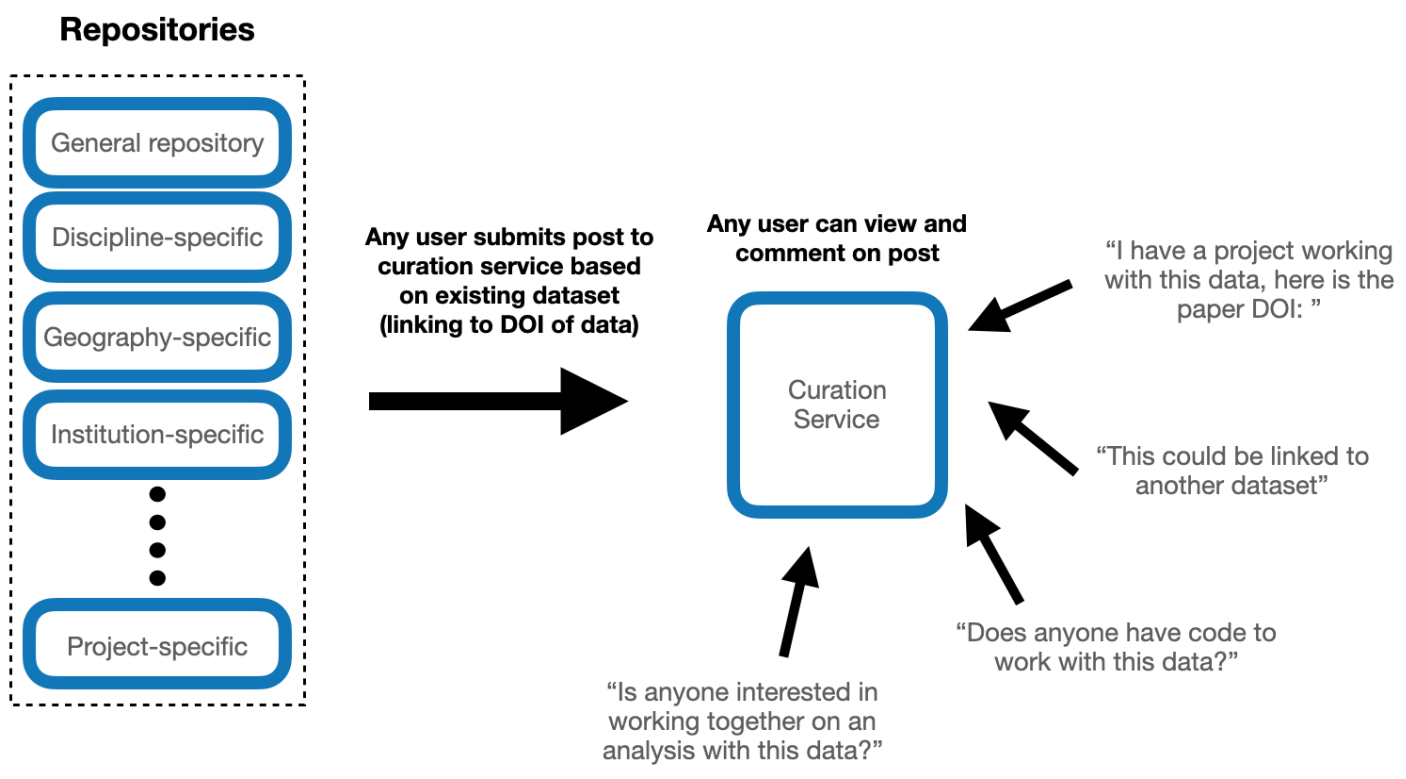

Figure 1: Schematic for repository and curation interface. 
${ }^{* * *}$ please note that this is a non-peer reviewed EarthArXiv preprint ${ }^{* * *}$

\section{Coastal Atlases}

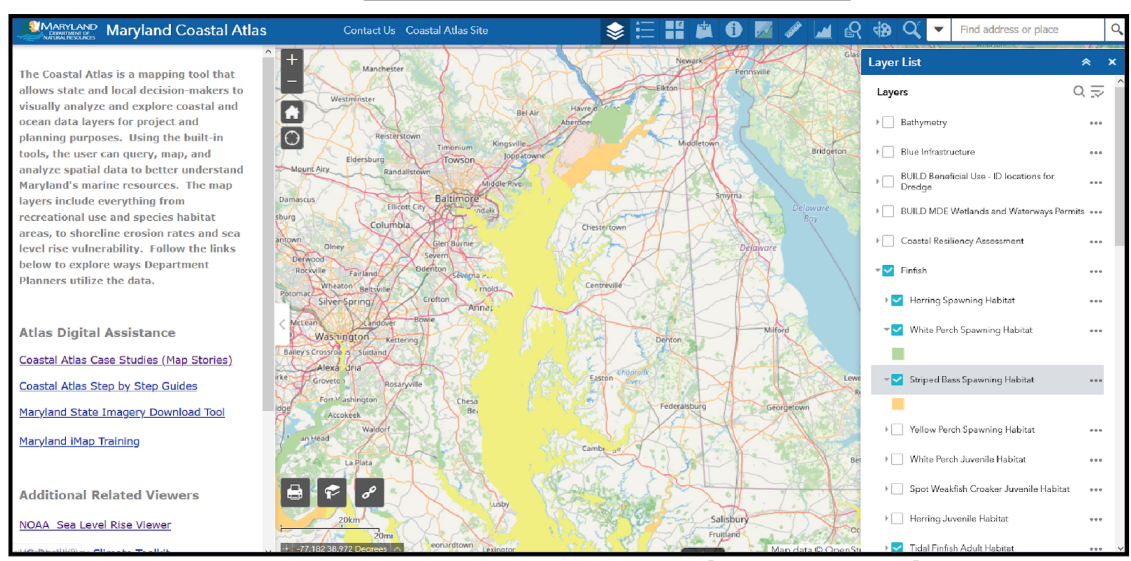

a) Maryland coastal atlas: Example of atlas interface

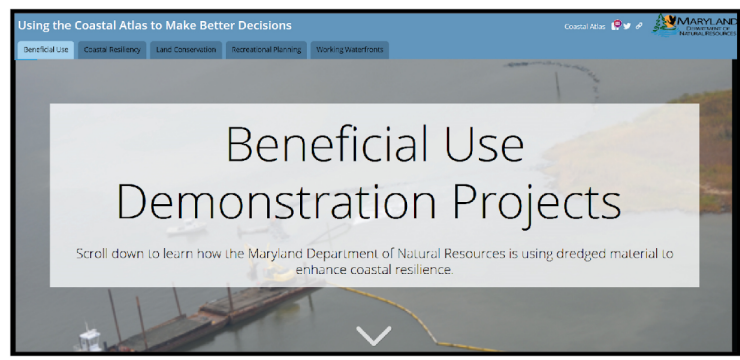

b) Use case demonstrating application of coastal data; Maryland Coastal atlas

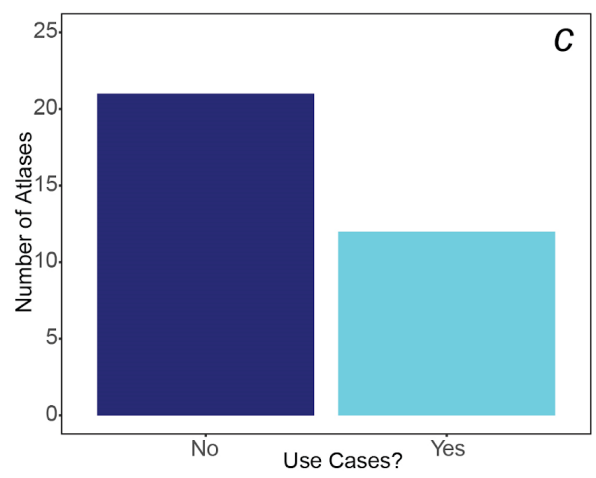

Figure 2: Example of a Coastal Atlas. A third of atlases provide example use cases for the data. 
${ }^{* * *}$ please note that this is a non-peer reviewed EarthArXiv preprint ${ }^{* * *}$
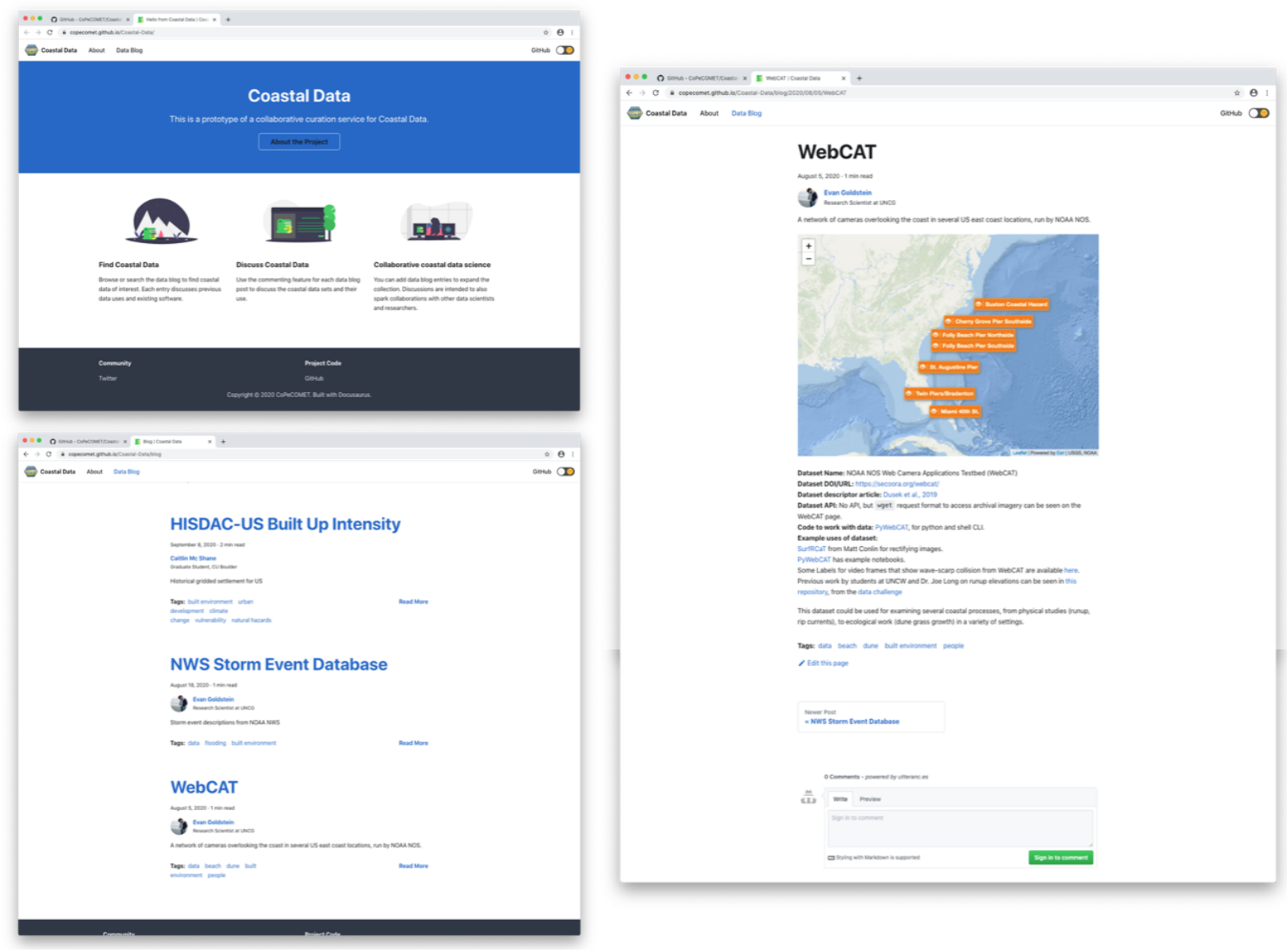

Figure 3: Our minimal, prototype example of a deployed curation service. Top left, the splash page. Bottom left, example of dataset entries with tags. Right, example of a dataset entry with links to the original data, examples of code and use of the data. 
Supplementatarable_atasses

\begin{tabular}{|c|c|c|c|c|c|c|c|}
\hline & & & & & & & \\
\hline Maryland Coastal Atlas & 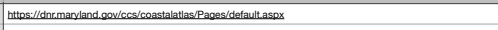 & 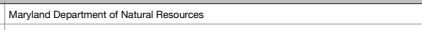 & Yes & Yres & No & No & \\
\hline Alaska Coastal Atlas & Underc constraction & NA & Yes & $\mathrm{NA}$ & $\mathrm{NA}$ & NA & 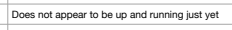 \\
\hline 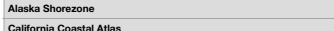 & 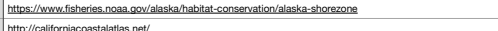 & 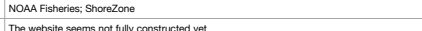 & Yes & No & No & ros & \\
\hline 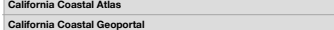 & 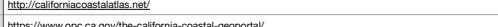 & 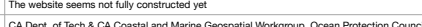 & Yess & NA & NA & Na & 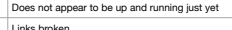 \\
\hline 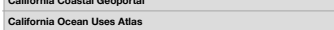 & 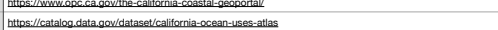 & 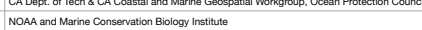 & $\begin{array}{l}\text { Yes } \\
\text { Yes }\end{array}$ & No & $\begin{array}{lll}N_{0} \\
\text { Na }\end{array}$ & NA & 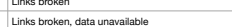 \\
\hline Corat Heath Alatas & & 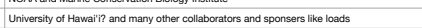 & Yes & No & No & yes & \\
\hline Datat Basin Consoration Bilobyy hastututo & 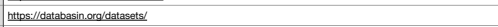 & 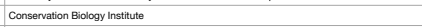 & Yes & res & No & ves & \\
\hline Great Lakes Commission & 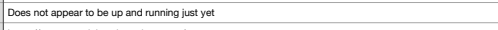 & Great Lakes Commisision & Yes & res & NA & NA & 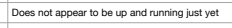 \\
\hline Great Lakes Shoreviewer & 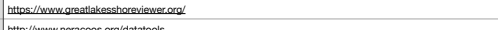 & 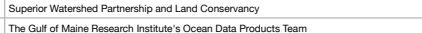 & Yes & NA & NA & Na & Website not working \\
\hline 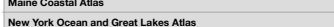 & 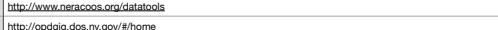 & 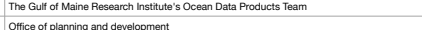 & Yes & Nos & No & Nos & \\
\hline 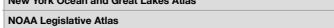 & 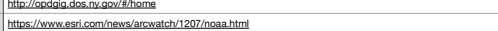 & $\begin{array}{l}\text { offico of planning and developmentt } \\
\text { NOAA }\end{array}$ & Yes & Yas & $\begin{array}{l}\text { No } \\
\text { NA }\end{array}$ & Ves & Links Broken \\
\hline 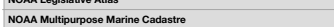 & 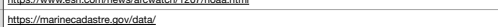 & NOAA & Yes & yes & & Yes & Linke Broten \\
\hline North Carolina Cosasta Atas & 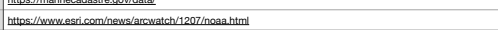 & East Carolina University & Yres & $\mathrm{Na}$ & Na & NA & Links Broken \\
\hline North Carolina Coastat Hazards Decision Portal & 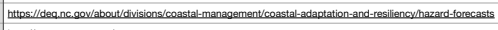 & NC Dopatment of Environmental Gually & Yese & res & No & No & \\
\hline Northwest Asso o o N Networted Occan Observing Systems & 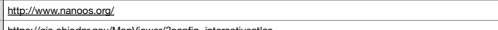 & 1005 Association plus others & Yes & no & No & Yos & \\
\hline $\begin{array}{l}\text { Ohic Coastat AAlas } \\
\text { Oregon Coasta Altas }\end{array}$ & 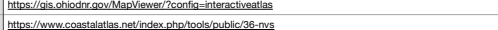 & 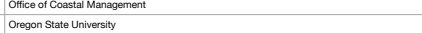 & Yess & $\begin{array}{l}\text { Yes } \\
\text { No }\end{array}$ & $\begin{array}{l}\text { No } \\
\text { Na }\end{array}$ & $\begin{array}{l}\text { No } \\
\text { No }\end{array}$ & \\
\hline Orogon Explorer: North Cosast Explorer & 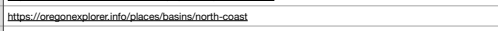 & 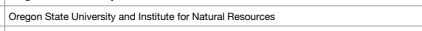 & Yes & res & No & res & \\
\hline Partnership for Intercisicipininary Studies of Coastal oceans & 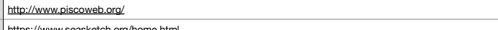 & 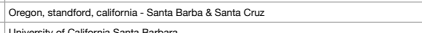 & Yes & res & res & res & \\
\hline 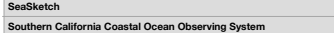 & 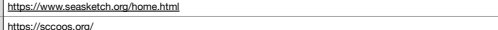 & $\begin{array}{l}\text { University of Caltorian Santa alatara } \\
\text { us loos }\end{array}$ & Yes & Noes & No & No & 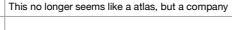 \\
\hline 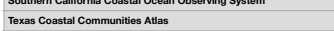 & 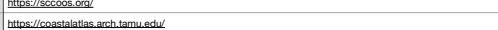 & $\begin{array}{l}\text { US lioos } \\
\text { Texas Sustanable Coastal Intititive }\end{array}$ & Yros & No & $\mathrm{NA}$ & No & Links Broken \\
\hline 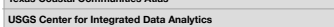 & 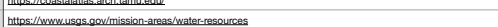 & 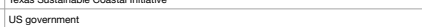 & res & ves & No & res & Linse Broken \\
\hline Virginia Cosstal Coospatiata and Educational Mapping System & 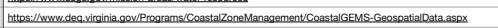 & 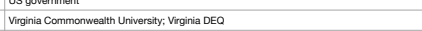 & No & Noes & No & No & \\
\hline Virginia Institute of Marine Science & 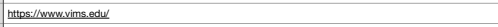 & Virginia Institte of Marine Science & Yes & No & No & NA & \\
\hline $\begin{array}{l}\text { Wastington Coastat Atas } \\
\text { water Alts }\end{array}$ & 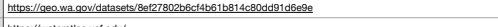 & Wastington State & Yes & Yes & No & No & \\
\hline $\begin{array}{l}\text { Water thas } \\
\text { West Cost occan Data Portal }\end{array}$ & 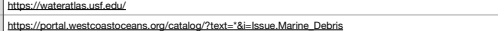 & 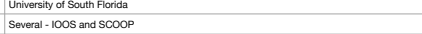 & Yess & $\begin{array}{l}\text { No } \\
\text { Yes } \\
\text { S }\end{array}$ & No & $\begin{array}{l}\text { No } \\
\text { No }\end{array}$ & \\
\hline Wisconsin Coasta Atas & 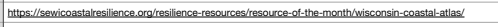 & University of Wisconsin & Yes & No & No & res & \\
\hline New Hampshire Coasta A Alas & 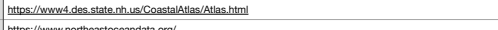 & 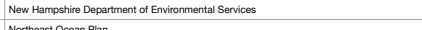 & No & No & No & No & \\
\hline 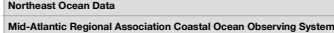 & 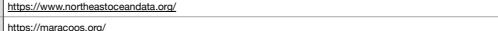 & 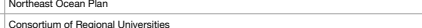 & No & $\begin{array}{l}\text { Yes } \\
\text { Yes }\end{array}$ & No & res & \\
\hline Massels & 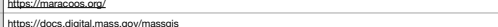 & 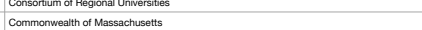 & No & sos & No & No & \\
\hline lecticut Environmental Conditic & 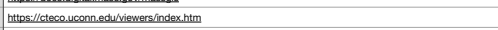 & 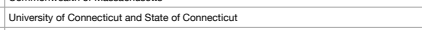 & No & Yes & 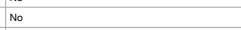 & 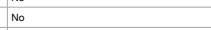 & \\
\hline Rhode Istand Map Room & 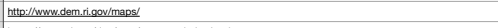 & 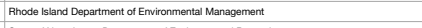 & No & res & No & No & \\
\hline $\begin{array}{l}\text { Now Jersey Coastat Atass } \\
\text { South Carolona Waterseds Atans }\end{array}$ & 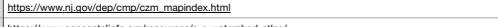 & Statat of N New Jersey Department of Em & No & Yes & No & Not & \\
\hline Forida Keys National Marins Sanctuar D Digtata A Alas & 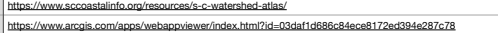 & 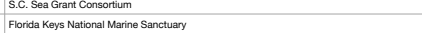 & No & yes & No & No & \\
\hline Gulf of Mexico Data Atas & 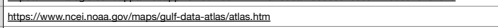 & 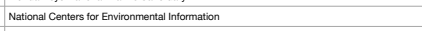 & No & No & No & No & \\
\hline Wassinington State Coasta Alass & 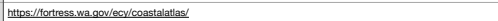 & Wastington State Departmer of Ecology & No & No & No & No & \\
\hline
\end{tabular}

